
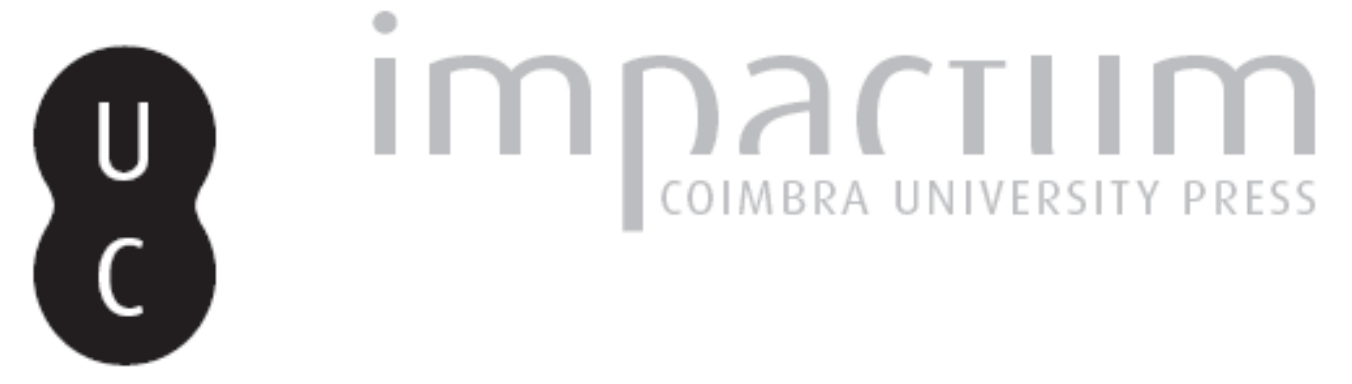

\title{
Nota sobre um dolium da herdade da Machoqueira
}

\author{
Autor(es): $\quad$ Nolen, Jeannette U. Smit
}

Publicado por: Imprensa da Universidade de Coimbra

URL persistente:

URI:http://hdl.handle.net/10316.2/45655

DOI:

DOI:https://dx.doi.org/10.14195/1647-8657_24_4

Accessed : $\quad$ 26-Apr-2023 15:44:24

A navegação consulta e descarregamento dos títulos inseridos nas Bibliotecas Digitais UC Digitalis, UC Pombalina e UC Impactum, pressupõem a aceitação plena e sem reservas dos Termos e Condições de Uso destas Bibliotecas Digitais, disponíveis em https://digitalis.uc.pt/pt-pt/termos.

Conforme exposto nos referidos Termos e Condições de Uso, o descarregamento de títulos de acesso restrito requer uma licença válida de autorização devendo o utilizador aceder ao(s) documento(s) a partir de um endereço de IP da instituição detentora da supramencionada licença.

Ao utilizador é apenas permitido o descarregamento para uso pessoal, pelo que o emprego do(s) título(s) descarregado(s) para outro fim, designadamente comercial, carece de autorização do respetivo autor ou editor da obra.

Na medida em que todas as obras da UC Digitalis se encontram protegidas pelo Código do Direito de Autor e Direitos Conexos e demais legislação aplicável, toda a cópia, parcial ou total, deste documento, nos casos em que é legalmente admitida, deverá conter ou fazer-se acompanhar por este aviso.

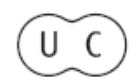


FACULDADE DE LETRAS

INSTITUTO DE ARQUEOLOGIA

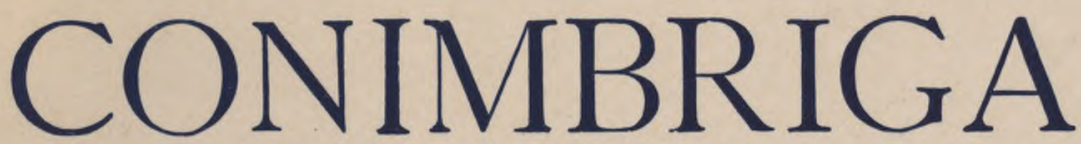

VOLUMEXXIV

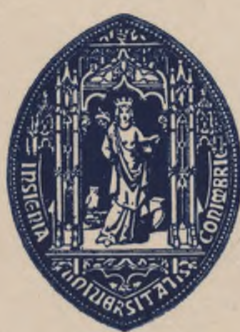

UNIVERSIDADE DE COIMBRA

1985 
JEANNETTE U. SMIT NOLEN

Arqueóloga

NOTA SOBRE UM DOLIUM DA HERDADE DA MACHOQUEIRA «Conimbriga», XXIV (1985), p. 105-109

RESUmo : Estuda-se um dolium que foi encontrado, intacto, numa herdade dos arredores de Évora, onde aparecem outros vestígios da ocupação romana. 0 recipiente pode datar-se dos séculos iv ou v da nossa era.

SUMmaRY: A perfectly preserved Dolium is here presented. It was found near Évora, in the South of Portugal, on a country estate where other remains of a Roman occupation have come to light. It is datable to the 4 th. or 5 th. century A.D. 
(Página deixada propositadamente em branco) 


\section{NOTA SOBRE UM DOLIUM DA HERDADE DA MACHOQUEIRA}

É raro encontrar intacto um vaso da época romana, e é ainda mais raro encontrar um dolium em perfeito estado de conservação, impecável, como é o caso deste da Herdade da Machoqueira (concelho de Évora, freguesia de N. ${ }^{a}$ Sr. $^{a}$ de Machede). É, por conseguinte, com muito prazer que o apresentamos.

O dolium foi encontrado, por acaso, quando um burro tropeçou num buraco do terreno pedregoso, na parte mais alta da herdade. Vendo que o buraco era fora do vulgar, o dono do burro examinou-o de perto e verificou que se tratava de uma talha enterrada. Felizmente, nem o burro, nem o dolium ficaram magoados neste feliz acidente, e o vaso nem sequer se partiu ao ser desenterrado.

Este dolium não é o único vestígio da época romana encontrado na Herdade da Machoqueira; também uma placa funerária, dedicada a M(arcus) APPVLEIV[S], atribuída ao séc. i da nossa era pelo Doutor J. $\mathrm{d}^{\wedge}$ ncarnaçãoP), faz parte do património antigo deste monte.

Fizemos uma pequena pesquisa no local donde foi retirada a talha (em data que desconhecemos). Aí achámos abundantes tegulae e imbrices e também fragmentos de cerâmica, tanto do tipo «comum» não datável, como terra sigillata sud-gálica e hispânica e terra sigillata clara «C»e «D» $\left.{ }^{2}\right)$. Este último fragmento é de boa

p) Agradecemos-lhe a informação, ainda inédita no momento em que redigíamos esta nota. Foi publicada na sua obra Inscrições Romanas do Conventus Pacensis (= IRGP), Goimbra, 1984, sob o n. ${ }^{\circ} 387 \mathrm{a}$, p. 464.

(2) T. S. S. G.: fragmento do bordo dum prato da forma Dragendorff 15/17, do período flaviano;

T. S. H.: fragmento do bordo duma tigela da forma Dragendorff $24 / 25$, do período flaviano-domiciano;

T. S. Clara «C» e «D»: fragmentos dos fundos de pratos de formas irreconhecíveis. 
qualidade, de parede delgada e pasta fina, datável dos fins do séc. ui ou inícios do séc. iv.

A cerâmica documenta, pois, uma ocupação duradoura do sítio: desde meados do séc. i até, pelo menos, finais do séc. $m$ d.C. Também a família Apuleia parece ter tido uma certa importância na região: M. Appuleius pode ser um imigrante itálico ou um descendente dos primeiros imigrantes na Lusitânia $\left(^{3}\right)$.

\section{O DOLIUM}

Forma: Bordo engrossado e revirado sobre o ombro, duas asas pequenas, bojo ovoide, fundo quase raso.

Decoração: Uma linha incisa em ziguezague, delimitada por dois «riscos» horizontais ao nível das asas.

Dimensões: Alt.: 52,2 cm.; diâm. máx.: $55,1 \mathrm{~cm}$.

Pasta: micácea, bem classificada, com abundância de elementos não argilosos de fracção grande/média. Os elementos não argilosos são constituídos por grãos subangulosos de quartzo (muito abundante), feldspato (poucos), mica moscovítica (muitos), minerais ferromagnesianos (muito abundantes) e fragmentos de óxido de ferro. Encontram-se também alguns grãos poliminerais.

Esta pasta é comparável a outras de origem alentejana, como por exemplo a pasta I de Sto. André $(4)$.

Cor: laranja acastanhado, Munsell 2.5 YR 2/4-6 (5).

Superficie da base: alisada com uma pedra.

Cronologia: séc. iv (?)-v d.C.

$\left.{ }^{3}\right)$ Informação de José d'Encarnação. Registam-se, no conventus Pacensis, mais dois outros membros da gens Appuleia: um em Alcácer do Sal (IRCP 190), outro em Ervedal (Avis) (IRCP 437).

(4) J. U. S. Nolen, L. F. Dias, A Necrópole de Stê. André, Parte II, Os Materiais, «Conimbriga», XX, 1981, p. 33-178, p. 65-70.

(5) Munsell Soil Color Charts, Baltimore, Maryland, 1975. 
Paralelos: M. Vegas, Cerámica común romana del Meditteráneo occidental (Publicaciones eventuales, 22), Barcelona, 1973; tipo 49-6, fig. 42, p. 117-118. Este dolium provém de Tarragona, do estrato D, e é datável de principios do séc. v d.C. J. DE Alarcão, Cerâmica comum local e regional de Conimbriga, Coimbra, 1974, n. ${ }^{\circ}$ 928, p. 127, est. LII, de cronologia «tardo-romano».

Alarcão, na p. 127, faz referencia a outro dolium com decoração de «um risco ondulado que lhe ornamenta os ombros entre duas caneluras», encontrado numa camada de destruição no criptopórtico de Conímbriga. 
Esт. 1

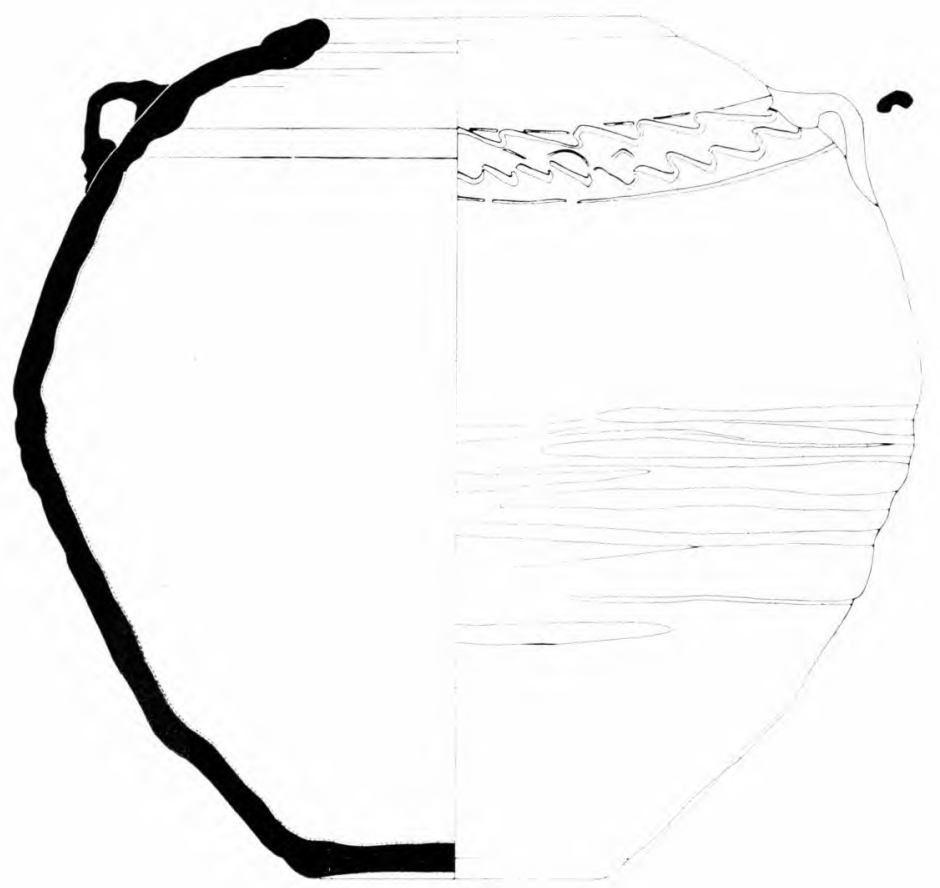


Est. 2

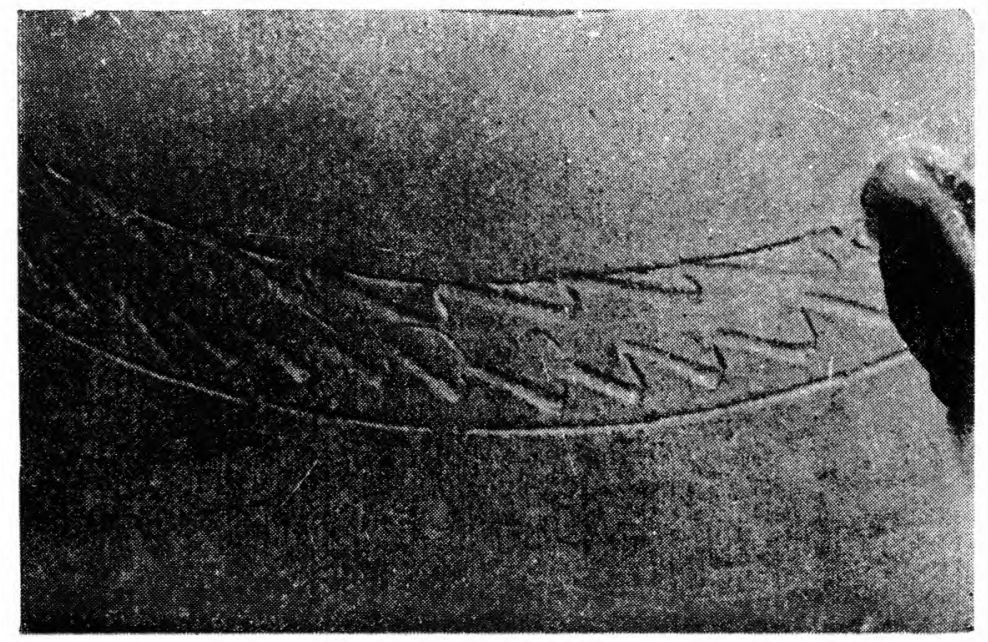

